\title{
El nomen sacrum ihs como símbolo de la crucifixión en el Sermón de la Circuncisión del Señor de san Vicente Ferrer
}

\section{The nomen sacrumits as a symbol of the Crucifixion in the Sermon of the Circumcision of the Lord by Saint Vincent Ferrer}

\author{
María LuZ Mandingorra Llavata \\ m.luz.mandigorra@uv.es \\ http://orcid.org/0000-0001-7263-4043 \\ Universitat de València
}

\begin{abstract}
Resum: El nomen sacrum ihs se hallaba presente en infinidad de manifestaciones artísticas y objetos de la vida cotidiana durante la Edad Media, por lo que era bien conocido por los fieles. El objetivo del presente artículo es mostrar de qué modo san Vicente Ferrer se sirve de esta abreviatura como símbolo de la crucifixión de Jesucristo con el fin de fomentar la devoción al nombre Iesus y erradicar el recurso a adivinos y sortílegos. Para ello, analizaremos el sermón de la Circuncisión del Señor predicado por el maestro dominico y estableceremos la conexión de los elementos integrantes del texto con representaciones coetáneas de la crucifixión.
\end{abstract}

Paraules clau: san Vicente Ferrer, predicación, Nomina Sacra, crucifixión, historia de la cultura escrita

\begin{abstract}
The nomen sacrum ihs was present in many paintings as well as other artifacts during the Middle Ages, therefore, it was very well known by the public. The aim of this paper is to show the way Saint Vincent Ferrer uses this abbreviation as a symbol of the Crucifixion of Jesus Christ in order to increase the devotion to the Name of Jesus and prevent people from consulting diviners and sorcerers to solve daily life problems. To this end, we analyse the Sermon of the Circumcision of the Lord preached by the Dominican master and establish the relationship between the elements that compose the text and some contemporary images of the Crucifixion.
\end{abstract}

Keywords: Saint Vincent Ferrer, preaching, Nomina Sacra, crucifixion, history of literacy 
María Luz Mandingorra Llavata. El nomen sacrum iłs como símbolo de la crucifixión en el Sermón de la Circuncisión del Señor de san Vicente Ferrer

\section{Introducción}

«Proposui pro luce habere illam» es el tema de los sermones predicados por Vicente Ferrer en la festividad de santa Lucía. ${ }^{1}$ En la introducción previa a la divisio thematis, integrada por las cuatro cualidades que, como la luz, tuvo la santa - Pulchritudinem sine deformitate; Largitudinem sine tenacitate; Rectitudinem sine diliquitate; Longitudinem sine retarditate» (Gimeno \& Mandingorra 2006: $\mathrm{n}^{\circ} 37$, 92) - el maestro destaca la importancia del nombre en la definición de las características de los individuos, lo que es particularmente relevante en el caso de los santos, por cuanto constituye la fuente de sus virtudes, a la vez que las sintetiza y facilita su recuerdo por parte de los fieles:

\footnotetext{
Ex illa divine providentie est quod quelibet sancta persona iuxta proprietates et virtutes quas habitura est sortiatur et nomen. Ratio est propter nostram recordationem, scilicet ut perfectio sanctitatis extense per vitam uno vocabulo breviter teneatur, sicut tota materia libri in titulo designatur (Gimeno \& Mandingorra 2006: no 37, 92).
}

Puesto que la vida humana no es sino un libro: «nam quaterna sunt anni et menses, et folia septimane, et cartule dies; et si quis nacitur de nocte est scriptus in pagina nigra, et si de die in pagina alba», cuando Dios dispone la santidad de una persona «iam ponit in intencione patris et matris ut ponant illi nomen consonum vite sancte cuius debet esse» (Gimeno \& Mandingorra 2002: $\mathrm{n}^{\circ} 144,546$ ).

El libro como metáfora de la vida es una de las innumerables figuras utilizadas por san Vicente para dar expresión a los conceptos por medio de evidencias habituales, estableciendo un paralelismo entre la cualidad simbólica del universo y la realidad cotidiana (Mandingorra 2021: 471-472). Estas imágenes procedían de todos los ámbitos del conocimiento, así como de la experiencia y actividades humanas: astronomía, geometría, filosofía natural, cinegética, gastronomía, vida social, etc. y servían tanto para mostrar el método que iba a utilizar para estructurar el sermón -el del jurista, ${ }^{2}$ el del maestro de obras, ${ }^{3}$ el del agricultor, ${ }^{4}$ etc.-, como para hacer comprensibles los complejos contenidos doctrinales que deseaba transmitir a los fieles.

Por otro lado, a lo largo del proceso de elaboración de su prédica, Vicente Ferrer era consciente de que el sermón era un eslabón de un circuito de información más complejo que incluía la oralidad, la escritura y la imagen, el llamado triángulo de la expresión medieval (Zumthor 1989: 152). Sabía muy bien que la transmisión del mensaje religioso se basaba en la redundancia: el discurso oral de la predicación se ayudaba de la imagen, que aportaba una dimensión visual a los procesos de comprensión y memorización y que, además, podía ir acompañada por secuencias textuales. Puesto

\footnotetext{
1 Sap 7, 10 (Perarnau 1999: n 674, 722-723). Para las citas latinas de la Biblia se ha seguido la edición Biblia (1985).

2 Véase, por ejemplo, Gimeno \& Mandingorra (2006: nº 458, 595).

3 Véase, por ejemplo, Gimeno \& Mandingorra (2002: nº 53, 226).

4 Véase, por ejemplo, Gimeno \& Mandingorra (2019: $\left.n^{\circ} 72,992\right)$.
}

SCRIPTA, Revista internacional de literatura i cultura medieval i moderna, núm. 17 / juny 2021 / pp. 16-35 ISSN: 2340-4841 · doi:10.7203/SCRIPTA.17.20946 
que palabra, texto e imagen bebían de las mismas fuentes, el éxito de la comunicación quedaba garantizado mediante esta constante recurrencia de la información.

Ello se advierte perfectamente en el sermón correspondiente a la festividad de la Circuncisión, cuyo tema es «Apparuit benignitas et humanitas Salvatoris» (Tit 2, 3). En el tercer punto de la diviso thematis, que aparece formulada de modos distintos en la tradición manuscrita e impresa - «impositio nominis virtuosi», «donation de nom virtuós», «llamación de fama virtuosa», «donació de nom virtuós» (Perarnau 1999: n 34, 492-493) - trata la cuestión del nombre Iesus con el fin de desentrañar su auténtico significado -Salvador- y, como veremos, lo hace a partir del nomen sacrum iћs. El objetivo de este artículo es, por consiguiente, analizar de qué modo y por qué motivo san Vicente construye su argumento en torno a una representación gráfica como es la abreviatura iћs, utilizada en el registro textual desde la Antigüedad, que se hallaba presente en infinidad de objetos y era empleada como invocación en documentos de la vida cotidiana como albaranes o libros de cuentas, por lo que era fácilmente reconocible por el público.

\title{
La devoción al nombre Iesus
}

La devoción al nombre Iesus aparece en innumerables sermones de san Vicente, ya que su predicación era un deber ineludible para todo evangelizador, de acuerdo con el ejemplo de san Pablo, ${ }^{5}$ quien lo cumplió incluso después de ser decapitado:

\begin{abstract}
Tamen beatus Paulus etiam post mortem suam predicavit et laudavit Deum Christum, nam cum fuit decapitatus, caput eius dicebat: "Iesus!". Et statim natus fuit quidam fons aque. Et cum secundo dixiset: “Iesus!", iterum natus fuit alius fons aque. Et tercio, cum dixiset: "Iesus!", iterum natus est alius fons aque; et ita beatus apostolus Paulus predicavit post mortem, quod non fecerunt alii, sed solum in vita sua (Gimeno \& Mandingorra 2002: no 87, 358).
\end{abstract}

La necesidad de predicar el nomen Iesus radica en las infinitas virtudes que Dios puso en él: «E vejau què us diré: que totes quantes virtuts Déus ha posades en pedres, ni en erbes, ni en steles, ni en àngels, més ne ha posades e més n'a en aquest nom de Jesús que en totes aquelles» (Sanchis \& Schib 1971-88: I, 173). De acuerdo con el maestro valenciano, que para la elaboración de los Sermones de sanctis se inspira en fundamentalmente en la liturgia y en la Leyenda áurea, muchos milagros de los santos fueron debidos al recurso que hicieron al nombre Iesus. Así, pone en boca de san Mateo: «No pensets que yo puga resuscitar, que hom só mortal; mas per virtut del nom de Jesús pens-me que

\footnotetext{
5 Debemos tener presente que san Vicente afirma de él que «pro nobis predicatoribus, posumus dicere quod beatus Paulus magis propius observavit verbum quod dixit Christus apostolis [Mc 16, 15]: "Euntes in universum mundum docentes", etc. "creature", quam ceteri apostoli qui per provincias, etc.». (Gimeno \& Mandingorra 2002: n 87, 356). El tema del sermón, de hecho, es «Fratres, notum vobis facio Evangelium», Gal 1, 11 (Perarnau 1999: n 360, 609); el autor recoge la variante «Notum vobis facio Evangelium» (1999: n 590, 691).
} 
María Luz Mandingorra Llavata. El nomen sacrum iłs como símbolo de la crucifixión en el Sermón de la Circuncisión del Señor de san Vicente Ferrer

aquest resuscitarà» (Sanchis \& Schib 1971-88: IV, 58), y de Santiago apóstol afirma que, mientras era conducido a su ejecución, curó a un paralítico: «Lo Senyor per qui yo vayg a morir, te dono sanitat en virtut del seu nom: Jesús!» (Sanchis \& Schib 1971-88: II, 207). Por su parte, san Juan evangelista resistió el martirio de la caldera de aceite hirviente diciendo: «Iesus, Marie filius, sit mihi clemens et propicius» (Gimeno \& Mandingorra 2002: $n^{\circ}$ 58, 251). Del mismo modo, es el nombre Iesus el que, por su virtud, mantiene jóvenes las almas (Sanchis \& Schib 1971-88: I, 174) y los elementos como el sol y la luna que «tan jóvens se són com lo primer dia» (Sanchis \& Schib 1971-88: IV, 177). Pese a todo, es su valor apotropaico el que más destaca en los sermones de san Vicente.

Uno de los pecados individuales convertido en comunitario y más atacado por el predicador dominico cuando trata la «gobernación ideal de las ciudades» (Cátedra 1994: 233) es cualquier forma de magia y hechicería que, según afirma, es un medio por el que Dios tienta a los individuos con el objeto de medir su devoción: «quando est magna fama de aliquo homine so $<\mathrm{r}>$ tilego seu incantatore, scilicet quia facit magnas curationes quas Deus operatur ut temptet vos, et parat subtiliter ut videat quid facietis» (Gimeno \& Mandingorra 2019: $\mathrm{n}^{\circ}$ 31, 470). Por ello, son recurrentes las recomendaciones a las autoridades locales para que no toleren la presencia de adivinos y sortílegos: «Et ideo, rectores istius communitatis, provideatis ut notorii divini, etc. non sustineantur, quia audio quod hic est quedam iudea divina et coniuradora» (Gimeno \& Mandingorra 2002: $\mathrm{n}^{\circ}$ 178, 788); «Ideo, tales divini, etc. notorii, quando gentes processionaliter vadunt ad eos, debent extirpari per dominos et rectores communitatum» (Gimeno \& Mandingorra 2019: $\mathrm{n}^{\circ} 18$, 318). Su presencia, como la de las prostitutas, era considerada causa de grandes calamidades: «e no anar a sortillers ne sostenir aquells, car sostenir aquest peccat és bastant a donar tempestats, pedra, sequedat e semblants coses» (Sanchis \& Schib 1971-88: V, 43). Dado que se acudía a ellos para resolver cuestiones prácticas de la vida cotidiana, ${ }^{6}$ resultaba imprescindible ofrecer un procedimiento alternativo, de forma que el nombre Iesus se presentaba como un mecanismo para la solución de todo tipo de problemas, frente a las falsedades y supersticiones:

\footnotetext{
Sed modo sunt multi qui ponunt spem in falsis coniurationibus, aliqui observant dies egipciacos, etc. Item mulieres faciunt sortilegia dicendo: «Tres Marias à en 1 prat». Item que la partiera non senhe la manda. Item ponentes spem en mascas, dicendo quod ponant las bragas a la porta. Et ideo, dimissis istis stultitiis, ponatis totam spem in nomine Iesu, etc. (Gimeno \& Mandingorra 2019: $\left.\mathrm{n}^{\mathrm{o}} 88,1170\right)$.
}

Así, por ejemplo, se recomendaba para favorecer la concepción de hijos o para evitar los dolores del parto: «Et ideo, mes filles, de matrimonio si vultis habere prolem, non accedatis ad divinos, sed cum nomine Iesus et cruce super ventre qualibet mane et vespere faciatis» (Gimeno \& Mandingorra 2002: no 89, 363). Ahora bien, entre todas las dificultades que se podían superar de este modo, la más importante, por ser también la más grave, era la curación de enfermedades, tanto de las personas como de los animales: «Item, faciendo cum nomine Iesus et signo crucis cum devocione super infirmitate, vel dolore, vel llaga. Et non dubitetis, si cum devocione facitis et suaviter, quod habebitis in brevi

6 Sobre esta cuestión, véanse, entre otros, Boscá (1991); Narbona (1998); Castell (2013). 
María Luz Mandingorra Llavata. El nomen sacrum i†s como símbolo de la crucifixión en el Sermón de la Circuncisión del Señor de san Vicente Ferrer

sanitatem, etc.» (Gimeno \& Mandingorra 2002: $\mathrm{n}^{\circ}$ 178, 788); «Si algun hom ha alguna nafra, no y digats degun conjur, sinó lo nom de Jesús, fent la creu. Més vos diré: que a les bèsties aprofite tal empastre» (Sanchis \& Schib 1971-88: III, 303).

Las propiedades curativas del nombre Iesus enlazan de un modo directo con la figura de Cristo médico, una asimilación que ya realiza san Agustín ${ }^{7}$ y que constituye una de las imágenes más queridas por san Vicente:

\begin{abstract}
Modo volo vobis predicare totum cursum medicine quem Christus servat in curatione animarum (...) Si ergo aliquis dicitur medicus, quia habet scientiam et practicam, et, cum Christus habeat, ideo bene potest dici medicus, et ipsemet vocat se medicum (Gimeno \& Mandingorra 2019: $\mathrm{n}^{\circ}$ 56, 788).
\end{abstract}

De ese modo, el nomen Iesus se convirtió en uno de los innumerables recursos que el individuo medieval utilizaba "para protegerse de los peligros que le acechaban», no todos, como se ha dicho, dentro de los márgenes de la ortodoxia religiosa (Español 2011: 166). ${ }^{8}$ No sorprende, en consecuencia, que apareciera en aderezos y medallas destinados a proteger a los niños y en infinidad de objetos de la vida diaria (Español 2011: 173-176), como vajillas, ${ }^{9}$ cofres $^{10}$ o pavimentos cerámicos, ${ }^{11}$ junto con otras fórmulas como «Ave Maria». ${ }^{12}$

Como hemos visto, el procedimiento que se debía seguir consistía, en todos los casos, en decir «Iesus» al tiempo que se realizaba el signo de la cruz, tal como hacía san Marcos quien «cum dicebat "Iesus", senper inclinabat capud et osculabatur crucem factam cum policibus et manibus. Et hoc in publico, sed in secreto faciebat crucem in terra et osculabatur ibi» (Gimeno \& Mandingorra 2002: $\mathrm{n}^{\circ} 45$, 193). No obstante, su eficacia se fundamentaba en la devoción sincera de quienes lo practicaban: «L'oli és medicinal, specialment oli de oliva, e serveix a moltes malalties; axí lo nom de Jesús, que a tota plaga és bo, si tu hi has devoció» (Sanchis \& Schib 1971-88: I, 173. Por ello, el nomen Iesus debía estar custodiado en el corazón de cada fiel, como hizo san Ignacio, «in cuius corde post eius obitum

\footnotetext{
7 Agustín, Santo (1845a: col. 1708): «Quomodo solent medici potentiam suae artis in desperatis ostendere: sic Dominus Jesus Christus, medicus et salvator noster, in desperato, qui persecutor Ecclesiae fuit, ostendit magnitudinem artis suae» (In Psalmum CXXX Enarratio. Sermo ad plebem); (1846: col. 1668): «Ipse medicus, ipse medicamentum: medicus, quia Verbum; medicamentum, quia Verbum caro factum est» (Sermo CCCLXXIV. De Epiphania Domini, II). Para un análisis de cómo se refleja la práctica médica en los sermones de san Vicente véase Ferragud (2018).
}

8 Para la conexión entre la magia y la medicina en la Edad Media, puede verse la síntesis de Montero (2000).

9 Por ejemplo, el braserillo azul con reflejo metálico conservado en el Museo Lázaro Galdiano, no inventario 00122.

10 Hallamos un testimonio en el inventario de bienes de Arnau de Valleriola, doctor en leyes de Valencia, realizado entre el 10 y el 26 de marzo de 1463: «Item, hun mich cofre groch, en lo qual ha scrit IHS», Archivo del Colegio de Corpus Christi de Valencia (=ACCV), Protocolos notariales, Pere Calaforra, notario, no 013629.

11 Por ejemplo, el azulejo conservado en el Museo Arqueológico Nacional (=MAN), nº inventario 60002.

12 Como el plato de la serie del Ave María, que se conserva en el MAN, $\mathrm{n}^{\circ}$ inventario 51109.

SCRIPTA, Revista internacional de literatura i cultura medieval i moderna, núm. 17 / juny 2021 / pp. 16-35 ISSN: 2340-4841 ·doi:10.7203/SCRIPTA.17.20946 
María Luz Mandingorra Llavata. El nomen sacrum iłs como símbolo de la crucifixión en el Sermón de la Circuncisión del Señor de san Vicente Ferrer

inventus est nomen Iesus literis aureis scriptum» (Gimeno \& Mandingorra 2019: nº 88, 1170).

Con todo, las propiedades del nomen Iesus se derivan de su significado oculto, secreto, que debe ser desvelado por el predicador para la iluminación y provecho de los fieles. Y san Vicente lo hará en el sermón correspondiente a la festividad de la Circuncisión:

In hac die que est caput anni sancta mater Ecclesia facit festum circumcisionis Domini, quam hodie voluit recipere propter rationes quas declarabo. Materia erit satis speculativa et continet multa secreta, sed, si bene vultis attendere, optime eam intelligetis (Ferrer 1485: h. $h_{7} v$ ).

\section{El sermón de la festividad de la Circuncisión del Señor}

De acuerdo con Perarnau (1999: $n^{\circ}$ 34, 492-493), el texto latino del sermón está recogido en los manuscritos conocidos como Sermonario de Perugia, ${ }^{13}$ Sermonario de Aviñón ${ }^{14}$ y Sermonario del Patriarca, ${ }^{15}$ además de en la edición príncipe de los Sermones de tempore et de sanctis, impresa en Colonia en 1485 y atribuida a Heinrich Quentell. ${ }^{16}$ La redacción más antigua corresponde al manuscrito de Perugia, pero, dado que se trata de una colección de esquemas, el texto solo ofrece los contenidos doctrinales básicos y omite la explicación que permite hacerlos comprensibles al público. ${ }^{17}$ Por otra parte, la más completa es la incluida en la edición príncipe de Colonia, seguida por la contenida en el manuscrito de Aviñón y, finalmente, por la del Patriarca, que, sin embargo, presenta un par de diferencias significativas en su planteamiento. ${ }^{18}$ Por ello, tomaremos como referencia la versión impresa y, cuando proceda, efectuaremos las remisiones correspondientes a las variantes de las diversas redacciones manuscritas.

En el Sermonario de Perugia -como se ha indicado, el más antiguo que incluye el sermón-el tema, «Apparuit benignitas et humanitas Salvatoris», se articula en la divisio como sigue:

Susceptio caracteris dolorosi, ibi: "Apparuit benignitas";

Effusio sanguinis pretiose, ibi: "Apparuit humanitas";

Impositio nominis virtuosi, ibi: "Salvatoris" (Gimeno \& Mandingorra 2006: n 56, 122).

Es el tercer punto, por consiguiente, el que el maestro dedica al nomen Iesus, del que ya se indica su

13 Perugia, Convento dei Domenicani, ms. 477. Ed.: Gimeno \& Mandingorra (2006, no 56, 122-123).

14 Aviñón, Bibliothèque Municipale, ms 610. Ed.: Gimeno \& Mandingorra (2019: nº 120, 1527-1537).

15 ACCV. Ed.: Gimeno \& Mandingorra (2002: n 162, 671-678).

16 Incunabula Short Title Catalogue (=ISTC) if00129000, Gesamtkatalog der Wiegendrucke (=GW) 9835.

17 Para la tradición manuscrita de los sermones vicentinos véase Gimeno (2019).

18 Su introducción no incluye la metáfora del libro ni las referencias a los padres y doctores de la Iglesia presentes en la edición de Colonia de 1485, aunque, a cambio, introduce las profecías de Isaías 7, 14 y Habacuc 3, 18, ausentes en las otras dos versiones. Por otro lado, tampoco sigue la estructura en tres puntos (interpretación, pronunciación y representación) que sí encontramos en el manuscrito aviñonés y en la edición príncipe.

SCRIPTA, Revista internacional de literatura i cultura medieval i moderna, núm. 17 / juny 2021 / pp. 16-35 ISSN: 2340-4841 · doi:10.7203/SCRIPTA.17.20946 
María Luz Mandingorra Llavata. El nomen sacrum iłs como símbolo de la crucifixión en el Sermón de la Circuncisión del Señor de san Vicente Ferrer

significado: Salvador. Pese a su brevedad, destaca dos cuestiones fundamentales en relación con aquel. En primer lugar, Iesus es el título del libro de la vida: «liber vite scriptus stilo hominis per Spiritum, scilicet habito homine colore rubeo, intitulatus est "Iesus"»; en segundo lugar, representa la crucifixión que hace posible nuestra salvación, por lo que debemos depositar en él nuestra veneración y nuestra esperanza: «representat Christi crucifixionem in qua fuit nostra salvatio, ideo venerandum et in eo sperandum est» (Gimeno \& Mandingorra 2006: ${ }^{\circ}$ 56, 122-123).

La redacción del manuscrito del Patriarca comienza señalando el significado de Iesus como Salvador: «nam Iesus non vult aliquid dicere, nisi salvadon» (Gimeno \& Mandingorra 2002: no 162, 676), mientras que tanto la edición príncipe como la del manuscrito de Aviñón inician su exposición precisando que en él se integran todas las virtudes de la creación: «quia omnes virtutes quas Deus posuit in herbis, lapidibus, verbis, planetis, stellis, constellacionibus, omnes sunt et continentur in hoc benedicto nomine Ihesus ${ }^{19}$ quod fuit hodie datum Christo» (Ferrer 1485: h. ${ }_{1}$ r). El texto de la edición príncipe fundamenta la elección del nombre en la autoridad de Tomás de Aquino afirmando «quod nomina debent proprietatibus rerum respondere» ${ }^{20} \mathrm{y}$ cita dos precedentes de las Sagradas Escrituras, uno del Antiguo Testamento, Abraham: «Nec ultra vocabitur nomen tuum Abram, sed appellaberis Abraham: quia patrem multarum gentium constitui te» (Gen 17, 5) y otro del Nuevo, san Pedro: «tu es Petrus, et super hanc petram aedificabo ecclesiam meam» (Mt 16, 18). A continuación, explica cómo «hoc nomen Ihesus significat naturam humanam, sed Christus naturam divinam» y vuelve a apoyarse en santo Tomás: «sicut hoc nomen Christus in quo intelligitur et divinitas ungens et humanitas uncta; sive solum divinam naturam, sicut hoc nomen Deus, vel filius Dei; sive solum naturam humanam, sicut hoc nomen homo, vel Iesus». ${ }^{21}$ Acto seguido -y aquí coincide con el texto de Aviñón- introduce el mencionado símil de Cristo como libro de la vida escrito por el Espíritu santo:

\footnotetext{
Videtur michi quod Spiritus sanctus tenuerit erga Christum modum quem tenent doctores vel scriptores erga librum, et, libro composito, imponunt sibi nomen vel titulum de litera rubea iuxta materiam de qua tractat liber, ut De anima vel De celo et mundo, et sic de aliis. Sic etiam Spiritus sanctus composuit et scripsit librum, scilicet corpus Christi (...) Magnus liber fuit Christus, quia existens in terra tangebat celum et non habebat titulum. Sed hodie, cum vermilione de illo cornu Spiritus sanctus ipsum intitulavit nomine Ihesus, nec habet aliud proprium nomen nisi istud (Ferrer 1485: h. i $_{1}$ ).
}

Finalmente, una vez situado adecuadamente en su contexto, procede a analizar cómo y por qué el nombre Iesus expresa la salvación humana en tres formas: en su interpretación, en su pronunciación y en su representación.

19 En la transcripción de los pasajes hemos mantenido la forma Ihesus utilizada en el incunable.

20 Tomás de Aquino (1903-1906: q. 37 a. 2 co. [48482]).

21 Tomás de Aquino (1903-1906: q. 16 a. 5 co. [47594]). Toda la quaestio 16 está dedicada a la naturaleza divina y humana de Jesucristo; el texto también cita Tomás de Aquino (1856-1858: lib. 3 d. 10-11 [8680-8888] y 1961: lib. 4 cap. 34 [27568-27598]).

SCRIPTA, Revista internacional de literatura i cultura medieval i moderna, núm. 17 / juny 2021 / pp. 16-35 ISSN: 2340-4841 $\cdot$ doi:10.7203/SCRIPTA.17.20946 
María Luz Mandingorra Llavata. El nomen sacrum iłs como símbolo de la crucifixión en el Sermón de la Circuncisión del Señor de san Vicente Ferrer

En lo que respecta al primer punto, su interpretación, tanto la redacción de Aviñón como la de Colonia se limitan a afirmar que «Ihesus interpretatur Salvator» (Ferrer 1485: h. i vv). Sí desarrollan, en cambio, el segundo, relativo a la pronunciación, con una extensión nuevamente desigual. El argumento parte de la división del nombre Iesus en dos sílabas. La primera, Ie, significa la humanidad de Cristo, dividida, a su vez, en dos elementos, el alma, indicada por la $I$, y el cuerpo, expresado en la e. Aquí la versión impresa se explaya e introduce las referencias a las correspondientes auctoritates sobre la unidad de cuerpo y alma, en concreto santo Tomás y san Agustín. ${ }^{22}$ Por otro lado, la segunda sílaba, sus, significa la divinidad de Cristo «propter accentum altum. Et habet tres litteras significantes triplicem honorem qui Christo debetur» (Ferrer 1485: h. $\mathrm{i}_{1} \mathrm{v}$ ), de acuerdo con lo que se afirma en Phil 2, 9-10: «Deus exaltavit illum, et donavit illi nomen, quod est super omne nomen: ut in nomine Iesu omne genu flectatur caelestium, terrestrium et infernorum». Curiosamente, las dos versiones resultan totalmente coincidentes cuando abordan el tercer punto, el referido a la representación. Ambas comienzan aludiendo a la práctica, común en la época, de disponer de una imagen de Cristo crucificado: «quilibet vult habere tabulam et ymaginem crucifixi» (Ferrer 1485: h. $i_{1} v$ ), para continuar señalando que una lectura atenta de la palabra Iesus muestra la crucifixión de la que deriva la salvación humana.

El manuscrito del Patriarca, cuya redacción, como hemos dicho, difiere de la que ofrecen tanto el sermonario aviñonés como la edición príncipe, proporciona inmediatamente la clave al afirmar: «nam Iesus debet scrivi VI, sicut ihs » (Gimeno \& Mandingorra 2002: no 162, 676). A partir de aquí, toda la exposición gira en torno a los elementos que integran el nomen sacrum. En primer lugar, la $h$ es el símbolo de Cristo crucificado, ya que «h non est littera, sed aspirationis nota». ${ }^{23}$ Irreconocible en la cruz $\backsim$ «quia vix cognoscebatun ${ }^{24}-$, Jesucristo no puede ser personificado por medio de una letra legible, al tiempo que «fuit aspirationis nota quando: "Clamans voce magna, suspiravit”, [Mt 27, 50]» (Ferrer 1485: h. $i_{1}$ v). Además, la propia morfología de la letra $h$, cuyo astil aparece cruzado por el signo abreviativo general (-) muestra a la perfección la figura de Cristo

22 Tomás de Aquino (1888-1889: q. 75 a. 4, [36806-36813]; 1856-1858: lib. 4 d. 44 q. 1 a. 1 qc. 2 [21252-21256]; 1950: lib. 2 y 7 [81839-81903] y [82811-83251]; 1956: Quodlibet II, q. 2 a. 2 [67059-67065]). Agustín, Santo (1845b: col. 626): «An vero nec anima sola, nec solum corpus, sed simul utrumque sit homo, cujus pars sit una sive anima sive corpus, ille autem totus ex utroque constet, ut homo sit» (Liber decimus nonus, caput III).

23 Tanto el manuscrito de Aviñón como la edición príncipe citan como fuente a Prisciano Cesariense, mientras que el sermonario del Patriarca se limita a afirmar vagamente «secundum Gramaticam sclavam», (Gimeno \& Mandingorra 2002: n¹62, 676). En todo caso, el pasaje no figura en la producción de dicho gramático, pero sí en otras obras, como, por ejemplo, Pseudo Marco Valerio Probo (2006: LLA 522.4, 50): «Nunc hoc monemus, quod h iuncta cum aliis mutis possit vocali concurrere et sonum syllabae suscitare, ut puta pulcher; et ideo hic aspirationis nota, id est sonus, non littera accipi debet, scilicet quoniam mutae coniunctae, si vocalibus occurrant, prohibentur sonum syllabae suscitare» $\mathrm{O}$ Remy d'Auxerre (2006: 225): «Latinae litterae non sunt plures quam X et VII, quia h non est littera sed aspirationis nota».

24 La redacción catalana del sermón en la colección del Archivo de la Catedral de Valencia proporciona una viva descripción del aspecto irreconocible de Jesucristo en la cruz, pues «tant fo pelat la barba e escopit ab gargallaços grossos, e sech e sanguinós» (Sanchis \& Schib 1971-88: VI, 254).

SCRIPTA, Revista internacional de literatura i cultura medieval i moderna, núm. 17 / juny 2021 / pp. 16-35 ISSN: 2340-4841 ·doi:10.7203/SCRIPTA.17.20946 
María Luz Mandingorra Llavata. El nomen sacrum i†s como símbolo de la crucifixión en el Sermón de la Circuncisión del Señor de san Vicente Ferrer

en la cruz: «in hac litera $h$ sunt tres liniationes, scilicet linea recta que significat animam Christi rectissimam; secunda est linea retorta que significat corpus Christi passibile et retortum in cruce; tercia linea est titel desuper que significat deitatem, que est super omnia» (Ferrer 1485: h. $i_{1} v$ ). Es significativa la asociación del signo abreviativo con la divinidad por su ubicación en la parte superior, aunque, como veremos a continuación, el origen cristiano del uso del guión para la indicación de las abreviaturas, en concreto, de los nomina sacra -que ha sido defendido, entre otros, por autores como Hurtado (2006a) o Bokedal (2014)-, pudo contribuir a esta vinculación. Por su parte, la letra $i$ representa al buen ladrón, situado a la derecha de Cristo, por dos motivos: su pequeño tamaño, que manifiesta su humildad al reconocer sus pecados, y su trazado recto, que denota su arrepentimiento. La letra $s$, en cambio, es la imagen del mal ladrón, crucificado a la izquierda de Cristo, ya que, «sicut hec litera s est retorta, sic ille latro fuit tortuosus et blasphemus» (Ferrer 1485: h. $i_{1} v$ ). Finalmente, los dos puntos que rodean la abreviatura deben ser interpretados como la virgen María y san Juan: «Duo puncta que fiunt in hoc nomine Iesus significant virginem Mariam et Iohannem evangelistam, quorum vita stabat in puncto propter dolorem passionis Christi» (Ferrer 1485: h. $i_{1} v$ ). Las tres redacciones concluyen en modo moral exhortando a la devoción por el nombre Iesus e insistiendo en la prohibición de acudir a adivinos y sortílegos. Cabe destacar que el texto del Patriarca, pese a ser más breve que los otros dos, se extiende más en este punto, remarcando sus propiedades curativas, que alcanzan incluso «iudeis et sarracenis, si volunt temptare et exprobare» (Gimeno \& Mandingorra 2002: $\mathrm{n}^{\circ}$ 162, 677).

\section{El nomen sacrum ihs y la crucifixión}

Son varias las razones que explican la utilización del nomen sacrum para desevelar el significado del nombre Iesus. La primera reside en el propio origen de la abreviatura. Fue Ludwig Traube quien acuñó la denominación nomina sacra para referirse a quince términos bíblicos y teológicos que eran abreviados por contracción entre los siglos I y II d. C., momento en que la escritura griega utilizaba el mecanismo de la suspensión para la abreviación de palabras. Estas abreviaturas -en particular

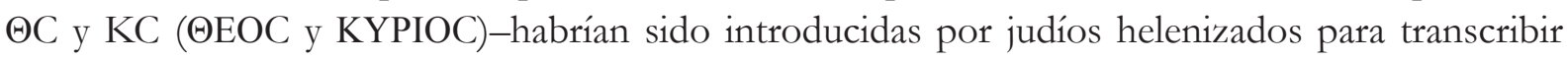
la palabra «dios», el Tetragrámaton, en sus traducciones del Antiguo Testamento al griego (1907: 27 y ss.). Así mismo, de acuerdo con el autor alemán, desde el siglo IV, serían adaptadas por la escritura latina en los textos cristianos, particularmente, para la copia de la Biblia (1907: 129-146). Y, en efecto, en manuscritos tardoantiguos como el Pentateuco Ashburnam ${ }^{25}$ o el De Trinitate de San Hilario de Poitiers, ${ }^{26}$ ambos del siglo VI, las escasas abreviaturas por contracción que aparecen

25 París, Bibliothèque Nationale de France (=BNF), ms Nouv. acq. lat. 2334. Objeto digital disponible en: https:// gallica.bnf.fr/ark:/12148/btv1b53019392c [Acceso 19/05/21].

26 París, BNF, ms Latin 2630. Objeto digital disponible en: https://gallica.bnf.fr/ark:/12148/btv1b10532595h [Acceso 19/05/21]. 
María Luz Mandingorra Llavata. El nomen sacrum i†s como símbolo de la crucifixión en el Sermón de la Circuncisión del Señor de san Vicente Ferrer

son nomina sacra. La misma pauta sigue el Salterio de Saint Germain ${ }^{27}$-un manuscrito purpúreo copiado con tinta de plata, contemporáneo de los anteriores- que, además, los destaca, al igual que las rúbricas, con tinta dorada, fijando así una clara jerarquía en el texto.

Investigaciones posteriores, sin embargo, han defendido el origen cristiano de los nomina sacra. Así Hurtado (2006a: 102-103) señala que, ciertamente, los textos del judaísmo desarrollaron diferentes estrategias para la traslación del Tetragrámaton, que podían ser un aviso al lector para no pronunciarlo y que esta práctica de no escribir el nombre divino o de hacerlo de un modo diferente se hizo extensiva también a los textos de dicha religión escritos en lengua griega. Ahora bien, de acuerdo con este autor, no existe en los manuscritos de ámbito judío un precedente directo del mecanismo abreviativo de los nomina sacra griegos, ya que la ubicación del signo que indica la abreviatura en la parte superior no se emplea en los textos precristianos salvo para la indicación de los numerales, de modo que los nomina sacra serían una innovación del mundo cristiano que, además, habría surgido en épocas muy tempranas de la difusión de sus textos (Hurtado 2006a: 109-112).

Por su parte, Bokedal (2014: 97 y ss.) afirma que el nomen sacrum más antiguo es IH/IHC, seguido de XPC -abreviaturas que se remontan a finales del siglo I d. C. o comienzos del s. II d. C.-, a las que se unirían inmediatamente después las de $\Theta E O C$ y KYPIOC. El autor destaca el hecho de que la primera abreviatura de Iesus es la suspensión IH, cuyo valor numérico es 18 y significaba «vida» en hebreo (2014: 104), por lo que habría sido una creación de escribas cristianos conocedores de la gematría (Hurtado 2006a: 120). Además, el análisis de los testimonios más antiguos, se trate de libros o de otro tipo de materiales, revela una muy temprana alternancia de las formas IH y IHC -que sería la dominante en la Antigüedad tardía y en la Edad Media- (Bokedal 2014: 95). En su opinión, reflejan una concepción binaria Dios/Jesucristo y los considera una forma de credo embrionario (Jesús, Cristo, Dios, Señor) que conformaría una guía para la fe. Igualmente, el hecho de que «salieran» de los textos bíblicos para ser utilizados en otros productos como grafitis e inscripciones, así como en las manifestaciones artísticas, revela su estatus como nombres sagrados en los textos (Bokedal 2014: 108-112). Es por ello que Hurtado (2006a: 96) afirma: «The nomina sacra are so familiar a feature of Christian manuscripts that papyrologists often take the presence of these forms as sufficient to identify even a fragment of a manuscript as indicating its probable Christian provenance».

Por otro lado, existe una coincidencia cronológica de este fenómeno con la aparición de otro elemento de representación visual, el estaurograma o cruz monogramática, formado por las letras

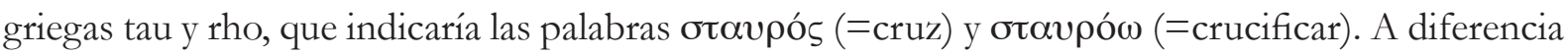
de IH, figura ya en textos precristianos y, al ser adoptado por los escribas cristianos -lo que se habría producido en torno al 200 d. C.-, asumiría nuevos significados y se convertiría, de hecho, en la referencia visual más antigua a Jesús crucificado, muy anterior a las primeras figuraciones de la

27 París, BNF, ms Latin 11947. Objeto digital disponible en: https://gallica.bnf.fr/ark:/12148/btv1b52507234j [Acceso 19/05/21].

SCRIPTA, Revista internacional de literatura i cultura medieval i moderna, núm. 17 / juny 2021 / pp. 16-35 ISSN: 2340-4841 $\cdot$ doi:10.7203/SCRIPTA.17.20946 
misma (Hurtado 2006b: 207-212), que Réau sitúa en el siglo VI (2008: 495).$^{28}$ Además de constituir técnicas de escritura, ambos - nomen sacrum y estaurograma- cumplen una función visual y, por ello, suponen un fenómeno iconográfico, una expresión visual y material de las primitivas fe y piedad cristianas (Hurtado 2006b: 225). Así, tanto los nomina sacra como la cruz monogramática forman parte del canon bíblico cristiano en sus aspectos materiales y textuales, constituyen marcadores de una identidad distintiva que, a su vez, indicarían de un modo visual el proceso de apropiación de los libros del Antiguo Testamento (Bokedal 2014: 88 y 107-109).

La inmersión del cristianismo en la cultura grecorromana favoreció el establecimiento de un binomio escritura-imagen, que se detecta ya desde el 200 d. C. y se desarrollaría entre los siglos III y IV (Tomás 1998: 30-31 y 45). El nacimiento de una iconografía cristiana surge de la necesidad de competir con las religiones coetáneas en dicho contexto cultural, que estaba habituado a la imagen como medio de expresión (Tomás 1998: 68-69) y cuando, a raíz de la crisis del siglo III, se produjo una caída drástica en el número de alfabetizados, las imágenes llegaron a convertirse en un instrumento didáctico imprescindible para la instrucción de los analfabetos. La necesidad de «superar el distanciamiento entre el mundo de los alfabetizados y el de los analfabetos, que ya era evidente y tan grave que incluso condicionaba las formas y el mismo éxito de la difusión del mensaje cristiano», llevó a la defensa, por Gregorio Magno entre otros, de una «cultura doble y, por lo tanto, de una producción cultural diferenciada en dos niveles distintos» (Petrucci 1999: 31-32). El carácter impenetrable que había adquirido el texto convirtió la imagen en un vehículo evangelizador, en la lectio de aquellos que eran incapaces de captar cualquier mensaje que exigiese una mínima capacidad de lectura:

\begin{abstract}
Aliud est enim picturam adorare, aliud per picturae historiam quid sit adorandum addiscere. Nam quod legentibus scriptura, hoc idiotis praestat pictura cernentibus, quia in ipsa ignorantes vident, quid sequi debeant, in ipsa legunt qui litteras nesciunt. Unde praecipue gentibus pro lectione pictura est. ${ }^{29}$
\end{abstract}

Esta concepción seguía vigente en el siglo XII, como muestra la exposición de Honorius Augustodunensis acerca de los valores de la imagen, que no era solo la «literatura de los laicos», sino un medio de estimular la memoria y, por lo tanto, una herramienta didáctica de primer orden:

Laquearium picturae sunt exempla justorum, quae Ecclesiae repraesentant ornamentum morum. $\mathrm{Ob}$ tres autem causas fit pictura: primo, quia est laicorum litteratura; secundo, ut domus tali decore ornetur; tertio, ut priorum vita in memoriam revocetur. ${ }^{30}$

28 Los Evangelios de Rábula, un manuscrito siríaco de dicha centuria, presentan en su f. 13r una bella imagen de la crucifixión, que muestra a Cristo aún vivo (Florencia, Biblioteca Medicea Laurenziana, cod. Plut. I, 56). Réau (2008: 496) apunta que las primeras representaciones de Cristo muerto en la cruz, en las que la cabeza cae y el cuerpo se desploma, no aparecen hasta el siglo XI.

29 Gregorio I (1849: col. 1128C, Liber Undecimus. Epistola XIII).

30 Honorius Augustodunensis (1854: col. 586C, Liber Primus. De missae sacrificio et de ministris Ecclesiae. Cap. CXXXII. De pictura). 
María Luz Mandingorra Llavata. El nomen sacrum iłs como símbolo de la crucifixión en el Sermón de la Circuncisión del Señor de san Vicente Ferrer

Paralelamente a este proceso tuvo lugar una «progresiva extensión de la simbología gráfica cristiana más allá de su temática original» que condujo a una percepción visual y «no verbal del significado del símbolo gráfico» (Petrucci 1999: 19). La sacralización de la escritura y la aparición de una concepción del libro sacro cristiano entre los siglos VI y VII diluyó parcialmente la abstracción propia de la escritura alfabética, lo que comportó una pérdida de la conciencia lingüística durante parte de la Alta Edad Media (Hoyo 2001: 320) que, a su vez, favoreció la codificación iconográfica de ciertas secuencias textuales, entre las que se hallaban, naturalmente, los nomina sacra. Al mismo tiempo, dichas secuencias se incorporaron paulatinamente a las imágenes, hasta el punto de que estos tituli comenzaron a asociarse con los motivos a los que acompañaban. Se advierte, por ejemplo, en los frontales de altar, como el de Farrera, datado en el primer tercio del siglo XIII, en el que los personajes sostienen cartelas con sus nombres, que, en el caso de Jesucristo, se expresa por medio de la abreviatura I $\hbar S .{ }^{31}$ Por su parte, los frontales de Mosoll, ${ }^{32}$ igualmente de comienzos del XIII, y de Cardet, ${ }^{33}$ de la segunda mitad del siglo, incorporan rótulos con las identificaciones de las figuras - en la parte superior de las escenas o insertos en las mismas-, que se sirven de nomina sacra como DñI o, por supuesto, I†S. ${ }^{34}$

De este modo, muchas abreviaturas y, en particular, el nomen sacrum i s, sumaron a sus valores alfabéticos una percepción visual como imagen. Su uso reiterado en las escrituras expuestas en los ámbitos públicos y privados propiciaba su reconocimiento por los fieles, por lo que resulta lógico que san Vicente se sirviera de él con el fin de transmitir y hacer comprensibles a un público mayoritariamente analfabeto el significado de Iesus como Salvador y, a la vez, fomentar su devoción como medio de eliminar el recurso a adivinos y sortílegos.

La descripción que el maestro dominico hace de la abreviatura -la $i$ y la $b$ minúsculas y la $s$ de doble curva- remite a la minúscula gótica textual, la escritura dominante en la producción del libro de la época y vinculada a la copia de los textos latinos, que se había introducido progresivamente desde mediados del siglo XIV en las escrituras expuestas, tanto en la pintura como en las inscripciones epigráficas o sobre objetos (Gimeno 1991: 507-508). Con esta forma, el nomen sacrum era, sin duda, bien conocido por los coetáneos de san Vicente, quienes lo habrían visto en infinidad de manifestaciones artísticas. Sin ánimo de ser exhaustivos, podemos citar el

31 Museu Nacional d'Art de Catalunya (=MNAC), no catálogo 015808-000. Objeto digital disponible en: https:// www.museunacional.cat/ca/colleccio/frontal-daltar-de-farrera/anonim/015808-000 [Acceso 19/05/21].

32 MNAC, $\mathrm{n}^{\mathrm{o}}$ catálogo 015788-000. Objeto digital disponible en: https://www.museunacional.cat/es/colleccio/ frontal-de-altar-de-mosoll/anonim-catalunya-taller-de-la-seu-durgell-del-1200/015788-000 [Acceso 19/05/21].

33 MNAC, no catálogo 003903-000. Objeto digital disponible en: https://www.museunacional.cat/es/colleccio/ frontal-de-altar-de-cardet/iohannes-taller-de-la-ribagorca/003903-000 [Acceso 19/05/21].

34 Similares características presenta el Frontal con escenas de infancia de Jesús del primer tercio del XIII, conservado en el Museo del Prado (=MP), no catálogo P008118. Objeto digital y ficha disponibles en: https://www.museodelprado.es/ coleccion/obra-de-arte/frontal-con-escenas-de-infancia-de-jesus/9894ac85-419a-47b2-85a7-6be95ee37e16 [Acceso 19/05/21].

SCRIPTA, Revista internacional de literatura $i$ cultura medieval i moderna, núm. 17 / juny 2021 / pp. 16-35 ISSN: 2340-4841 · doi:10.7203/SCRIPTA.17.20946 
María Luz Mandingorra Llavata. El nomen sacrum iłs como símbolo de la crucifixión en el Sermón de la Circuncisión del Señor de san Vicente Ferrer

retablo de san Miguel arcángel, atribuido a Joan Mates, del primer cuarto del siglo XV, que, sobre la tabla central que muestra a san Miguel matando al dragón, vemos a Cristo crucificado en una cruz rematada por una cartela con el nomen sacrum iћs. Además, las escenas superiores de los tres paneles aparecen rodeadas por iћs, escrito en bellas letras doradas. ${ }^{35}$ Hallamos una disposición similar en el contemporáneo retablo de la Virgen de la leche de Antoni Peris. En este caso, en la parte superior de sus tres tablas se observa cómo el nomen sacrum i†s campea sobre escudos sostenidos por ángeles que rodean el motivo central. ${ }^{36}$ Finalmente, por lo que se refiere a los objetos, además de en los mencionados con anterioridad, ${ }^{37}$ vemos, por ejemplo, la abreviatura iћs inscrita en tres de los cuatro rombos situados en el pie de la Cruz procesional gótica del siglo XIV conservada en el MBAV. ${ }^{38}$

Ahora bien, en muchas escrituras expuestas de la época siguieron utilizándose las mayúsculas góticas, tipo gráfico que se empleaba en este ámbito de escritura desde mediados del siglo XII, por lo que aún tenía una viva presencia a comienzos del Cuatrocientos. La morfología del nomen sacrum, con todo, no era muy distinta de la que hemos visto, ya que, en la mayúscula gótica, la $h$ adoptaba una forma minúscula y la $S$ tenía igualmente la forma de doble curva, por lo que la única diferencia sustancial radicaba en el hecho de que las tres letras eran del mismo tamaño. Se puede ver, por ejemplo, en el Calvario del MNAC, de mediados del siglo XIV, en el que de la cruz brota un árbol en el que se posa el pelícano eucarístico y a cuyo tronco se adhiere una cartela con la abreviatura IĤS. ${ }^{39}$ Por otro lado, en el Frontal del Corpus Christi conservado en el mismo museo, ${ }^{40}$ datado en los años centrales del XIV, IĤS aparece en las sagradas formas visibles en las distintas escenas de la tabla. Son muy parecidas las que encontramos en el Retablo del Corpus Christi, aunque, en este caso, la tabla central muestra una en el interior de un sagrario de diseño arquitectónico, rematado por una Crucifixión con la Virgen y san Juan sobrepuesta a la imagen de Cristo en majestad, que preside no solo la tabla, sino toda la obra. ${ }^{41}$ En la hostia custodiada

35 MNAC, $n^{\circ}$ catálogo 214533-000. Objeto digital disponible en: https://www.museunacional.cat/es/colleccio/ retablo-de-san-miguel-arcangel/joan-mates/214533-000 [Acceso 19/05/21].

36 Museo de Bellas Artes de Valencia (=MBVA), no inventario 240, 242, 243, 2409, 2844 y 4227. Su datación lo sitúa con anterioridad a 1415 (Benito 2003: no 15 30-31).

37 Véase supra, p.

38 MBVA, $n^{\circ}$ inventario 313. La cruz está datada en torno al año 1400, pero la caña del astil y el nudo, de forma globular, son de la segunda mitad del XIV (Benito 2003: $\left.n^{\circ} 22,44-45\right)$.

39 MNAC, $n^{\circ}$ catálogo 251558-000. Objeto digital disponible en: https://www.museunacional.cat/es/colleccio/ calvario/jaume-serra/251558-000 [Acceso 19/05/21].

40 MNAC, $n^{\circ}$ catálogo 009919-000. Objeto digital disponible en: https://www.museunacional.cat/es/frontal-delcorpus-christi [Acceso 19/05/21].

41 MNAC, $n^{\circ}$ catálogo 009920-000. Objeto digital disponible en: https://www.museunacional.cat/es/colleccio/ retablo-del-corpus-christi/mestre-de-vallbona-de-les-monges-guillem-seguer/009920-000 [Acceso 19/05/21].

SCRIPTA, Revista internacional de literatura $i$ cultura medieval i moderna, núm. 17 / juny 2021 / pp. 16-35

ISSN: 2340-4841 ·doi:10.7203/SCRIPTA.17.20946 
María Luz Mandingorra Llavata. El nomen sacrum iłs como símbolo de la crucifixión en el Sermón de la Circuncisión del Señor de san Vicente Ferrer

en el sagrario, el nomen sacrum está escrito en su variante IĤSS y escindido en dos elementos separados por la imagen de Cristo crucificado. ${ }^{42}$

La introducción de la escritura humanística a lo largo del siglo XV y, en particular, la recuperación de los modelos gráficos clásicos, afectó a la morfología del nomen sacrum en las escrituras expuestas. Una buena muestra nos la ofrecen las pinturas del Salvador Eucarístico de Joan de Joanes, de los años centrales del siglo XVI. En el primero de ellos, datado entre 1555 y 1565, Cristo sostiene en su mano izquierda un cáliz y en la derecha una hostia en la que aparece grabado IHSS. ${ }^{43}$ Idéntica estructura presenta el conocido como «el rubio», unos años posterior, aunque la forma carece del IĤS, que sí figura, no obstante, en el reverso de la tabla ${ }^{44}$. Finalmente, el Salvador Eucarístico que integraba el tabernáculo del altar de la capilla parroquial de San Pedro en la catedral de Valencia, sostiene la hostia con el IĤS, que también puede verse en el dorso de la pieza. ${ }^{45}$ En los tres casos se ha abandonado ya la minúscula gótica textual en favor de unas exquisitas capitales humanísticas, acordes con las tendencias estéticas y gráficas que se imponían progresivamente en Europa desde mediados del siglo XV (Gimeno 2007: 34-44 y 2015).

Por otro lado, san Vicente vincula el nomen sacrum a una imagen igualmente reconocible por el público: la crucifixión. Ciertamente, las representaciones de esta escena, fundamental en el pensamiento cristiano, evolucionaron a lo largo del tiempo (Réau 2008: 480-531). Aunque no entraremos en esta cuestión, que excede con mucho las posibilidades de estas páginas, sí señalaremos que el arte gótico desarrolló una compleja visión de carácter escenográfico calificada por el autor francés como «gran espectáculo» (Réau 2008: 513), que es solo parcialmente recogida por san Vicente al introducir, junto a la efigie de Jesucristo, dos parejas de actores: los ladrones y los dolientes (o los llorosos), esto es, la Virgen y san Juan. Es la que hallamos, por ejemplo, en la Crucifixión de Pietro Lorenzetti ${ }^{46}$-si bien con variaciones, ya que cuenta con más personajes-, datada entre 13401350, en la que, tal como explica san Vicente al identificarlo con la letra $h$, el cuerpo de Jesucristo se retuerce mientras de su costado brota la sangre mezclada con agua. También los dos ladrones presentan claras diferencias, que permiten su inmediato reconocimiento: el buen ladrón, Dimas, a quien Jesús «admitió en su reino» (Vorágine 2000: I, 217), exhibe una actitud de calma y resignación; joven e imberbe, ya goza de la gloria -indicada por el halo dorado- y baja los ojos como muestra de humildad, lo que permite equipararlo con la letra $i$. En cambio, el mal ladrón, Gestas, a quien

42 Para esta variante del nomen sacrum véase Traube (1907: 160-161).

43 MBAV, $\mathrm{n}^{\circ}$ inventario 297. Véase Benito (2000: $\mathrm{n}^{\circ}$ 32, 126-127).

$44 \mathrm{MBAV}, \mathrm{n}^{\circ}$ inventario 311. Véase Benito (2000: $\left.\mathrm{n}^{\circ} 33,128-129\right)$.

45 Museo de la Catedral de Valencia. Véase Benito (2000: nº 76, 180-181).

46 Nueva York, Metropolitan Museum, n inventario 2002.436. Objeto digital disponible en: https://www.metmuseum. org/it/art/collection/search/438605 [Acceso 19/05/21]. Muy similar es la Crucifixión que fuera atribuida a Duccio, di Boninsegna, hoy considerada obra de un artista perteneciente a su escuela. La pintura, datada en el primer tercio del siglo XIV, se conserva actualmente en la City Art Gallery de Manchester, no incorporación 1984.53. 
María Luz Mandingorra Llavata. El nomen sacrum iłs como símbolo de la crucifixión en el Sermón de la Circuncisión del Señor de san Vicente Ferrer

Jesús vio «caminar hacia su perdición» (Vorágine 2000: I, 217), cuenta con una barba hirsuta y «se retuerce entre las ligaduras como un Laocoonte apresado por serpientes» (Réau 2008: 514), lo que lo asemeja a la $s$. A los pies de la cruz, la Virgen y san Juan completan la imagen y contribuyen a conseguir un equilibrio compositivo, que en las ilustraciones más primitivas se obtenía por medio de otros elementos como el sol y la luna (Réau 2008: 518-519). La representación de la Virgen y san Juan solos junto a Cristo crucificado, la «Crucifixión con tres personajes» (Réau 2008: 512513), se encuentra con frecuencia en el ático de los retablos, como, por ejemplo, el ya citado de san Miguel arcángel, el de santo Tomás del $\mathrm{MNAC}^{47}$ o el Calvario atribuido al Maestro de Ávila conservado en el Museo del Prado. ${ }^{48}$ Así mismo, responden a este tipo las crucifixiones de Cimabue de la basílica de San Domenico de Arezzo y de la iglesia de la Santa Croce de Florencia, ambas de la segunda mitad del siglo XIII, en las que los dolientes aparecen de medio busto en los extremos del brazo horizontal de la cruz. Las numerosas variantes de la representación de la crucifixión en el tiempo, con la incorporación de personajes que, a su vez, desarrollaron unas formas propias, no afectaron, con todo, a los motivos esenciales de la escena, lo que, unido al propio carácter estático del nomen sacrum, contribuyó a convertirlos en vehículos ideales para la transmisión de los contenidos doctrinales.

La presencia habitual del nomen sacrum iłs en ámbitos muy diversos y la familiaridad que los fieles podían tener con el mismo, no significan que san Vicente no pudiera disponer de alguna imagen de la que servirse durante la predicación (Español 2019: 105 y ss.). La autora señala la existencia de retablos ligeros que podían montarse y desmontarse con facilidad, así como el hecho de que en las procesiones que acompañaban a los predicadores eran frecuentes las banderas con las Arma Christi, que podían estar presentes durante el sermón, en la tarima donde se instalaban el altar y el púlpito, sin olvidar que también podría recurrir a los elementos que le proporcionaba el mismo entorno urbano. No olvidemos que la potencia comunicativa del sermón exigía del predicador el uso de cuantos recursos estaban a su alcance. Por ello, y pese a sus reticencias hacia las interpretaciones que los pintores realizaban en ocasiones de las escenas, ${ }^{49}$ san Vicente era perfectamente consciente del impacto que la cultura visual tenía entre sus fieles (Español 2019: 118-129) y, en consecuencia, del valor didáctico y evocativo de las imágenes no solo de la pintura, la miniatura o la escultura, sino también de las relacionadas con otros objetos, así como las proporcionadas por la arquitectura y, en general, el paisaje. Todas ellas formaban parte de las evidencias cotidianas que convertían los

47 MNAC, $\mathrm{n}^{\mathrm{o}}$ catálogo 004378-000. Objeto digital disponible en: https://www.museunacional.cat/es/colleccio/ retablo-de-san-tomas/anonim-catalunya-girona/004378-000 [Acceso 19/05/21].

48 Madrid, MP, $\mathrm{n}^{\circ}$ inventario P002997. Objeto digital y ficha disponibles en: https://www.museodelprado.es/ coleccion/obra-de-arte/la-crucifixion/f7e2706b-fce1-4a14-9254-3be0540400b0 [Acceso 19/05/21].

49 Por ejemplo, en el caso de las figuraciones de la Virgen arrodillada en el Juicio final, de las que afirma que son un error, ya que María ocupará un trono a la diestra de Cristo: «Et dic quod virgo Maria stabit in sua catedra, sedendo ad latus dexterum Christi, licet quidam pintores ignari pintent eam flexis jenibus, et est error» (Gimeno \& Mandingorra 2002: $n^{\circ}$ 61, 263-264). Sobre las críticas del maestro a los pintores de la época, véase Toldrà (2002).

SCRIPTA, Revista internacional de literatura i cultura medieval i moderna, núm. 17 / juny 2021 / pp. 16-35 ISSN: 2340-4841 ·doi:10.7203/SCRIPTA.17.20946 
María Luz Mandingorra Llavata. El nomen sacrum iłs como símbolo de la crucifixión en el Sermón de la Circuncisión del Señor de san Vicente Ferrer

secretos doctrinales en contenidos asequibles para el público, estimulaban su reacción y favorecían su reforma moral y conversión.

La validez de la asociación del nomen sacrum iłs con la crucifixión se pone de manifiesto en el incremento de la veneración del nombre Iesus en las décadas siguientes a la muerte de san Vicente, por obra fundamentalmente de la predicación de Bernardino de Siena, uno de cuyos atributos es precisamente una tabla o disco solar con el anagrama IHS, que sostiene en la mano, a modo de talismán. Así lo muestra el retablo de Siena, obra de Sano di Pietro, en el que Bernardino sujeta con ambas manos la tabla mientras predica en la Piazza del Campo a una multitud de hombres y mujeres. ${ }^{50}$ Su discípulo Mateo de Agrigento llegó a tierras de la Corona de Aragón en 1426 (Rubió 1990: 48), predicó bajo la protección de la reina María y difundió la devoción por el nomen Iesus en la Corona de Aragón por medio de estampas que él mismo imprimía (Soldevila 1928: 276277). Su impacto fue tal ${ }^{51}$ que generó una polémica que, entre otras cosas, dio lugar al Tractatus ad Barcinonenses de littera $H$ in nomine Jesu de Andrea Biglia, en el que se cuestionaba el uso del nomen Iesus y, sobre todo, la devoción a la letra $b$ interpretada como Jesús crucificado (Rubió 1990: 5051). La polémica se zanjó con un Breve de Eugenio IV, de 5 de enero de 1432, en el que apoyaba la veneración del nombre de Jesús, si bien aún subsistieron reticencias hasta que Clemente VIII la incorporó oficialmente a la liturgia.

\section{Conclusión}

En su exposición acerca del significado auténtico del nombre Iesus como Salvador e incentivar su devoción con la finalidad última de acabar con el recurso a adivinos y sortílegos, san Vicente se sirve de la abreviatura ihs, en la que se combinan tanto elementos figurativos como textuales. El nomen sacrum se hallaba presente en numerosos objetos de todo tipo y era, por consiguiente, reconocible por los fieles, de manera que integraba el conjunto de evidencias cotidianas que el maestro utilizaba en su predicación al objeto de introducir las nociones doctrinales. Su codificación permitía a san Vicente tratarlo como una imagen que era asimilable a otra imagen, la de Cristo crucificado, igualmente familiar para el público. Pero, independientemente de sus valores comunicativos visuales, el predicador no pierde de vista la esencia textual del nomen sacrum y, por, ello, además de repasar los diversos componentes que integran cada uno de los signos y atribuirles un significado, recurre a la gramática para ayudar a su comprensión. De ese modo, reforzaba el mensaje de fondo, la significación del nomen Iesus, al tiempo que fomentaba su devoción y la confianza en sus valores apotropaicos.

50 Siena, Museo dell'Opera del Duomo.

51 De hecho, Arechaga \& Manglano (1985) se sirven de este fenómeno para establecer una cronología de la loza dorada en el siglo XV. 
María Luz Mandingorra Llavata. El nomen sacrum iłs como símbolo de la crucifixión en el Sermón de la Circuncisión del Señor de san Vicente Ferrer

\section{Bibliografía}

Agustín, Santo, Obispo de Hipona (1845a) Enarrationes in Psalmos. (C, G, S), en Migne, J. P. (ed.) Patrologiae Cursus Completus, sive bibliotheca universalis (...) omnium S.S. Patrum, Doctorum, Scriptorumque ecclesiasticorum qui ab aevo apostolico ad Innocentii III tempora floruerunt (...) Series Prima, vol. XXXVII, París, Venit apud Editorem, cols. 1033-1968.

- (1845b) S. Aurelii Augustini Hipponensis Episcopi ad Marcellinum De civitate Dei contra paganos Libri viginti duo. (C, S), en Migne, J. P. (ed.) Patrologiae Cursus Completus, sive bibliotheca universalis (...) omnium S.S. Patrum, Doctorum, Scriptorumque ecclesiasticorum qui ab aevo apostolico ad Innocentii III tempora floruerunt (...) Series Prima, vol. XLI, París, Venit apud Editorem, in via dicta d'Amboise, prope Portam vulgo d'Enfer nominatam, seu Petit-Montrouge, cols. 13-804.

- (1846) Classis V. Sermones Dubii. Quos inter qui visi sunt minus referre Augustinum, typis minutioribus exbibentur. (C, $G, S$ ), en Migne, J. P. (ed.) Patrologiae Cursus Completus, sive bibliotheca universalis (...) omnium S.S. Patrum, Doctorum, Scriptorumque ecclesiasticorum qui ab aevo apostolico ad Innocentii III tempora floruerunt (...) Series Prima, vol. XXXIX, París, Venit apud Editorem, cols. 1639-1718.

Arechaga Rodríguez-Pascual, C. de \& Manglano Baldoví, V. (1986) «El monograma IHS y el beato fray Mateo de Agrigento. Aportación a la cronología de la loza dorada del siglo XV», en Actas del I Congreso de Arqueología Medieval Española (17, 18, 19 abril 1985), Huesca, Diputación General de Aragón. Departamento de Educación y Cultura, pp. 559-570.

Auxerre, R. d' (2006) Commentum in Donati Artem maiorem, Múnich/Turnhout, K.G. Saur Electronic Publishing/Brepols. $<$ Bibliotheca Teubneriana Latina $>$.

Benito Doménech, F. (2000) Joan de Joanes: una nueva visión del artista y su obra, Valencia, Museu de Belles Arts.

Benito Doménech, F. (2003) (dir.) Museu de Belles Arts de València. Obra selecta, Valencia, Museu de Belles Arts.

Biblia (1985 [1ª ed. 1946]) Biblia Sacra iuxta Vulgatam Clementinam. Nova editio logicis partitionibus aliisque subsidiis ornata a Alberto Colunga OP et Laurentio Turrado, Madrid, Biblioteca de Autores Cristianos.

Bokedal, T. (2014) The Formation and Significance of the Christian Biblical Canon. A Study in Text, Ritual and Interpretation, Londres/Nueva Delhi/Nueva York/Sydney, Bloomsbury.

Boscá Codina, J. V. (1991) «Sortílegas, adivinas y conjuradores: indicios de una religiosidad prohibida», Revista d'Història Medieval, 2, pp. 63-76.

Castell i Granados, P. (2013) «"E cert té molt gran fama de bruixa e se fa metgessa e fa medecines". La demonización de las prácticas mágico-medicinales femeninas (siglos XIV-XVI)», Studia bistorica. Historia medieval, 31, pp. 233-244.

Cátedra García, P. M. (1994) Sermón, sociedady literatura en la Edad Media. San Vicente Ferrer en Castilla (1411-1412), Salamanca, Junta de Castilla y León.

SCRIPTA, Revista internacional de literatura i cultura medieval i moderna, núm. 17 / juny 2021 / pp. 16-35 
María Luz Mandingorra Llavata. El nomen sacrum iłs como símbolo de la crucifixión en el Sermón de la Circuncisión del Señor de san Vicente Ferrer

Español Bertran, F. (2011) «Las manufacturas artísticas como instrumento en los usos apotropaicos y profilácticos medievales», Clio \& Crimen, 8, pp. 165-190.

- (2019) «La cultura visual en los sermones de san Vicente Ferrer y en los escenarios de su predicación», Anuario de Estudios Medievales, 49/1, pp. 103-135. https://doi.org/10.3989/ aem.2019.49.1.04

Ferragud, C. (2018) «La enfermedad y la práctica médica en los sermones de Vicente Ferrer», eHumanista: Journal of Iberian Studies, 38, pp. 1-10.

Ferrer, Vicente Santo (1485) Sermones de tempore et de sanctis, Colonia [Heinrich Quentell]. 3 vol.

Gimeno Blay, F. M. (2007) «De la "luxurians littera" a la "castigata et clara". Del orden gráfico medieval al humanístico (siglos XV-XVI)», Litterae caelestes 2/1, pp. 9-51.

. (2015) «Mirce antiquitatis litterce quarenda. Poniendo orden entre las mayúsculas», en Castillo Gómez, A. (ed.) Culturas del escrito. Del Renacimiento a la contemporaneidad, Madrid, Casa de Velázquez, pp. 19-32.

- (2019) «Modelos de transmisión textual de los sermones de san Vicente Ferrer: la tradición manuscrita», Anuario de Estudios Medievales, 49/1, pp. 137-169. https://doi.org/10.3989/ $\underline{\text { aem.2019.49.1.05 }}$

Gimeno Blay, F. M. \& Mandingorra Llavata, M. L. (2002) Sermonario de san Vicente Ferrer del Real Colegio-Seminario del Corpus Christi de Valencia, Valencia, Ajuntament de València.

(2006) San Vicente Ferrer. Sermonario de Perugia. (Convento dei Domenicani, ms. 477), Valencia, Ajuntament de València.

—_. (2019) San Vicente Ferrer. Sermonario de Aviñón. Avignon. Bibliothèque Municipale ms 610, Valencia, Publicacions de la Universitat de València. 2 vol.

Gregorio I, Papa, Santo (1849) Sancti Gregorii Magni Registri Epistolarum (C, G, S), en Migne, J. P. (ed.) Patrologiae Cursus Completus, sive bibliotheca universalis (...) omnium S.S. Patrum, Doctorum, Scriptorumque ecclesiasticorum qui ab aevo apostolico ad Innocentii III tempora floruerunt (...) Series Prima, vol. LXXVII, París, Excudebatur et venit apud J.-P. Migne editorem, cols. 441A-1328C.

Honorius Augustodunensis (1854) Gemma animae sive De divinis officiis et antiquo ritu missarum, deque horis canonicis et totius annis solemnitatibus, en Migne, J. P. (ed.) Patrologiae Cursus Completus, sive bibliotheca universalis (...) omnium S.S. Patrum, Doctorum, Scriptorumque ecclesiasticorum qui ab aevo apostolico ad Innocentii III tempora floruerunt (...) Series Secunda, vol. CLXXII, París, Excudebatur et Venit apud J.-P. Migne editorem, in via dicta d'Amboise, prope Portam Lutetiae Parisiorum vulgo d'Enfer nominatam, seu Petit-Montrouge.

Hoyo, J. del (2001) «El crismón de la catedral de Jaca y la pérdida de la conciencia lingüística», en Albrete González, A. \& Macías Villalobos, C. (eds.) Actas del Congreso Internacional "Cristianismo y tradición latina” (Málaga, 2000), Madrid, Laberinto, pp. 317-322. 
María Luz Mandingorra Llavata. El nomen sacrum i†s como símbolo de la crucifixión en el Sermón de la Circuncisión del Señor de san Vicente Ferrer

Hurtado, L. W. (2006a) The Earliest Christian Artifacts. Manuscripts and Christian Origins, Grand Rapids, Michigan/Cambridge, U.K., William B. Eerdmans Publishing Company.

(2006b) «The staurogram in early christian manuscripts: the earliest visual reference to the crucified Jesus?», en Kraus, T. J. \& Nicklas, T. (eds.) New Testament Manuscripts. Their Text and Their World, Leiden, Brill, pp. 207-226.

Montero Cartelle, E. (2000) «De la Antigüedad a la Edad Media: medicina, magia y astrologia latinas», Cuadernos del CEMYR, 8, pp. 53-71.

Narbona Vizcaíno, R. (1998) «Tras los rastros de la Cultura Popular: hechicería, supersticiones y curanderismo en Valencia Medieval», Edad Media. Revista de Historia, 1, pp. 91-110.

Perarnau i Espelt, J. (1999) «Aportació a un inventari de sermons de Sant Vicent Ferrer: temes bíblics, títols i divisions esquemàtiques», Arxiu de Textos Catalans Antics, 18, pp. 479-811.

Petrucci, A. (2002) La concepción cristiana del libro entre los siglos VI y VII, Valencia, Universitat de València ("Arché", no 9).

Probo, Marco Valerio (Pseudo) (2006) Instituta artium, Múnich/Turnhout, K.G. Saur Electronic Publishing/Brepols. <Bibliotheca Teubneriana Latina $>$.

Réau, L. (2008 [1 $1^{\mathrm{a}}$ ed. 1996]) Iconografía del arte cristiano, tomo 1/volumen 2: Iconografía de la Biblia. Nuevo Testamento, Barcelona, Ediciones del Serbal. $3^{\text {a }}$ ed.

Rubió i Balaguer, J. (1990) «El beat fra Mateu d'Agrigento a Catalunya i a València: notes sobre la vida religiosa en una Cort del Renaixement», en Rubió i Balaguer, J. Humanisme $i$ Renaixement, Barcelona, Generalitat de Catalunya/Publicacions de l'Abadia de Montserrat, pp. 45-63.

Sanchis Sivera, J. \& Schib, G. (eds.) (1971-88) Sermons, Barcelona, Barcino. 6 vol.

Soldevila i Zubiburu, F. (1928) «La reyna Maria, muller del Magnànim», en Sobiranes de Catalunya: recull de monografies històriques [=Memorias de la Real Academia de Buenas Letras de Barcelona, 10], pp. 213-347.

Toldrà i Vilardell, A. (2002) «Sant Vicent contra el pintor gòtic», Afers, 41, pp. 37-55.

Tomás de Aquino, Santo (1856-1858) Scriptum super Sententiis. Textum Parmae editum ac automato translatum a Roberto Busa SJ in taenias magneticas denuo recognovit Enrique Alarcón atque instruxit, Parma, Corpus Thomisticum.

- (1888-1889) Summa Theologiae. Prima Pars. Textum Leoninum Romae editum ac automato translatum a Roberto Busa SJ in taenias magneticas denuo recognovit Enrique Alarcón atque instruxit, Roma, Corpus Thomisticum.

. (1903-1906) Summa Theologiae. Tertia Pars. Textum Leoninum Romae editum ac automato translatum a Roberto Busa SJ in taenias magneticas denuo recognovit Enrique Alarcón atque instruxit, Roma, Corpus Thomisticum.

- (1950) Sententia libri Metaphysicae. Textum Taurini editum ac automato translatum a Roberto Busa SJ in taenias magneticas denuo recognovit Enrique Alarcón atque instruxit, Turín, Corpus Thomisticum. 
María Luz Mandingorra Llavata. El nomen sacrum iћs como símbolo de la crucifixión en el Sermón de la Circuncisión del Señor de san Vicente Ferrer

Tomás de Aquino, Santo (1956) Quaestiones de quolibet. Textum Taurini editum ac automato translatum a Roberto Busa SJ in taenias magneticas denuo recognovit Enrique Alarcón atque instruxit, Turín, Corpus Thomisticum.

. (1961) Summa contra Gentiles. Textum Leoninum emendatum ex plagulis de prelo Taurini editum ac automato translatum a Roberto Busa SJ in taenias magneticas denuo recognovit Enrique Alarcón atque instruxit, Turín, Corpus Thomisticum.

Tomás, F. (1998) Escrito, pintado. Dialéctica entre escritura e imágenes en la conformación del pensamiento europeo, Madrid, Visor.

Traube, L. (1907) Nomina Sacra. Versuch einer Geschichte der christlichen Kürzung, Múnich, C. H. Beck'sche Verlagsbuchhandlung.

Vorágine, S. de la (2000) La Leyenda dorada, Madrid, Alianza Forma. 2 vol.

Zumthor, P. (1989) La letra y la voz: De la "literatura” medieval, Madrid, Cátedra. 